\title{
CREsCimento InICIAL DE Merremia cissoides, Neonotonia wightii E Stizolobium aterrimum ${ }^{1}$
}

\author{
Initial Growth of Merremia cissoides, Mucuna aterrima and Neonotonia wightii
}

CAMPOS, L.H.F. ${ }^{2}$, MELLO, M.S.C. ${ }^{3}$, CARVALHO, S.J.P. ${ }^{4}$, NICOLAI, M. ${ }^{5}$ e CHRISTOFFOLETI, P.J. ${ }^{6}$

\begin{abstract}
RESUMO - Este trabalho foi desenvolvido com o objetivo de avaliar o crescimento inicial de três espécies de plantas daninhas que são problemas emergentes para a cultura da cana-deaçúcar: Neonotonia wightii, Stizolobium aterrimum e Merremia cissoides. O delineamento experimental adotado foi inteiramente casualizado, com sete tratamentos e quatro repetições, para cada espécie estudada. Durante todo o experimento foram realizadas sete avaliações de crescimento (tratamentos), espaçadas de 15 dias, totalizando 105 dias de ciclo. As espécies tiveram suas variáveis analisadas, como a área foliar $\left(A f ; \mathrm{cm}^{2}\right.$ por planta). Posteriormente, o material amostrado foi seco em estufa, quando se mensurou também a matéria seca (g por planta) das raízes $(M r)$, da parte aérea $(M a)$ e total $(M t)$. O acúmulo de matéria seca observado mostra a elevada capacidade que a planta daninha $S$. aterrimum possui de produzir fitomassa. Ao final do experimento, observou-se estabilização da matéria seca da parte aérea $(M a)$ nas três espécies estudadas, acompanhada pela variável matéria seca total $(M t)$, com estabilização no final do experimento. Para S. aterrimum, obteve-se maior taxa de crescimento inicial e acúmulo de matéria seca total $(M t)$, além de maior acúmulo de área foliar (Af). N. wightii mostrou ser uma espécie de crescimento inicial lento, quando comparada com as outras estudadas. $M$. cissoides apresentou acúmulo significativo de matéria seca total ( $M t)$, quando comparado com as outras espécies.
\end{abstract}

Palavras-chave: análise de crescimento, biologia, matéria seca, área foliar

\begin{abstract}
This work aimed to evaluate the initial growth of three species of weed considered as emerging problems for sugarcane crop: Neonotonia wightii, Stizolobium aterrimum, and Merremia cissoides. The experiment was arranged in a completely randomized design, with seven treatments and four repetitions for each species studied. Seven growth evaluations (treatments) were carried out every 15 days, totaling a 105 day-cycle, followed by the analysis of the variables, such as leaf area (Af) given in ( $\mathrm{cm}^{2}$ per plant). The sampled material was dried in an oven, with the dry mass (g per plant) of the roots (Mr), the shoot (Ma) and total (Mt) being measured. The biomass accumulation observed shows the high ability of $\mathbf{S}$. aterrimum to produce biomass. At the end of the experiment, stabilization of the dry mass of the shoot (Ma) was observed for the three species, followed by the variable total dry mass (Mt) also showing stabilization at the end of the experiment. S. aterrimum presented the highest initial growth rate and total dry mass accumulation, besides the highest leaf area (Af). $\mathbf{N}$. wightii presented slow initial growth, while $\boldsymbol{M}$. cissoides showed a significant accumulation of total dry mass (Mt), compared with the other species.
\end{abstract}

Keywords: growth analysis, biology, dry mass, leaf area.

1 Recebido para publicação em 8.5.2011 e aprovado em 24.3.2012.

2 Mestre em Fitotecnia, Escola Superior de Agricultura "Luiz de Queiroz" - ESALQ/USP/Gestor de Tratos Culturais - USINA IRACEMA, <lhenrique.campos@terra.com.br>; ${ }^{3}$ Doutorando em Fitotecnia, ESALQ/USP, <melomsc@yahoo.com.br>; ${ }^{4}$ Professor, Dr., Instituto Federal do Sul de Minas Gerais, Campus de Machado, Caixa Postal 1.004, 37750-971 Machado-MG, <saul@mch.ifsuldeminas.edu.br >; 5 Engọ-Agrō., Dr., Pós-Doutorando, Dep. de Produção Vegetal, ESALQ/USP, $<$ mnicolai2009@gmail.com>; ${ }^{6}$ Professor Associado, Dep. de Produção Vegetal, ESALQ/USP, Av. Pádua Dias, 11, Caixa Postal 09, 13418-900 Piracicaba-SP, <pjchrist@esalq.usp.br>

Planta Daninha, Viçosa-MG, v. 30, n. 3, p. 497-504, 2012 


\section{INTRODUÇÃO}

Estudos sobre o comportamento e crescimento de plantas daninhas fornecem informações sobre padrões de crescimento vegetativo (Bianco et al., 1995). A Weed Science Society of America (WSSA) ressaltou que o conhecimento sólido sobre a biologia das plantas daninhas é a base para seu efetivo manejo, por meio de sistemas de manejo integrado (Oliver, 1997).

Informações sobre os diferentes estádios fenológicos e padrões de crescimento - fornecidas por estudos de crescimento e desenvolvimento das plantas daninhas - tornam possivel a análise do comportamento dessas plantas perante os fatores ecológicos, bem como sua ação sobre o ambiente, principalmente quanto à sua interferência sobre outras plantas (Lucchesi, 1984; Bianco et al., 1995). Radosevich et al. (1997) afirmam que a produção de matéria seca e o acúmulo da área foliar são reconhecidos como processos básicos no crescimento vegetal.

A habilidade de predição de estádios fenológicos, como florescimento, desenvolvimento e dispersão de sementes de plantas daninhas, pode auxiliar no desenvolvimento das práticas de manejo (Aguilera et al., 2004). Ainda, as características de crescimento de determinada espécie, como o crescimento da área foliar, oferecem um indicador de sua habilidade competitiva (Carvalho et al. 2005b).

Observações de campo têm apontado as espécies Neonotonia wightii e Stizolobium aterrimum como plantas daninhas com altas infestações e dificuldades de manejo em várias áreas produtoras de cana-de-açúcar no Brasil (Kuva et al., 2007), sobretudo em áreas anteriormente ocupadas por pastagens em consorciação com soja perene ( $N$. wightii) e/ou áreas de cana-de-açúcar (Saccharum spp.) manejada em rotação com mucuna-preta ( $S$. aterrimum) durante as reformas dos canaviais (Pereira, 2001). Esses problemas ocorrem também com as espécies de corda-de-viola, como assim são chamadas plantas dos gêneros Ipomoea e Merremia, com destaque para a espécie Merremia cissoides, que é conhecida pela dificuldade de seu controle em áreas de cana crua (Azania et al., 2009).

No entanto, pouco se conhece sobre a biologia dessas espécies, especialmente sobre aspectos de crescimento. Nesse sentido, este trabalho foi desenvolvido com o objetivo de avaliar o crescimento inicial de três espécies de plantas daninhas consideradas potenciais problemas para a cultura da cana-de-açúcar: $N$. wightii, S. aterrimum e $M$. cissoides.

\section{MATERIAL E MÉTODOS}

Um experimento foi desenvolvido em casa de vegetação (22 $42^{\circ} 30^{\prime \prime}$ de latitude sul, $47^{\circ} 38^{\prime} 00^{\prime}$ de longitude oeste e $546 \mathrm{~m}$ de altitude), no período entre agosto e novembro de 2010. Todas as unidades experimentais foram constituídas por vasos plásticos com $190 \mathrm{~mm}$ de diâmetro, $150 \mathrm{~mm}$ de altura e capacidade para 2,8 litros. O solo utilizado, de textura franco-arenosa, foi coletado em área experimental pertencente à ESALQ/USP, sendo peneirado para a retirada de torrões. As características químicas do solo estão apresentadas na Tabela 1. O fundo dos vasos foi vedado com papel-filtro para evitar a perda de solo, que poderia proporcionar heterogeneidade às parcelas.

O delineamento experimental adotado foi inteiramente casualizado, com quatro repetições e sete datas de avaliação do crescimento, espaçadas de 15 dias, totalizando 105 dias de ciclo; e três foram as espécies de plantas daninhas: $M$. cissoides, $N$. wightii e $S$. aterrimum.

Tabela 1 - Propriedades químicas ${ }^{1 /}$ do solo utilizado nos experimentos

\begin{tabular}{|c|c|c|c|c|c|c|c|c|c|c|c|}
\hline MO & P resina & $\mathrm{K}$ & $\mathrm{Ca}$ & $\mathrm{Mg}$ & $\mathrm{H}+\mathrm{Al}$ & $\mathrm{Al}$ & SB & CTC & $\mathrm{V}$ & $\mathrm{m}$ & $\mathrm{pH}$ \\
\hline$\left(\mathrm{g} \mathrm{dm}^{-3}\right)$ & $\left(\mathrm{mg} \mathrm{dm}^{-3}\right)$ & \multicolumn{7}{|c|}{$\left(\mathrm{mmolc} \mathrm{dm}^{-3}\right)$} & \multicolumn{2}{|c|}{$(\%)$} & $\left(\mathrm{CaCl}_{2}\right)$ \\
\hline 27 & 9 & 1,7 & 26 & 9 & 22 & 0 & 36,7 & 58,7 & 63 & 0 & 5,0 \\
\hline
\end{tabular}

1/ MO - matéria orgânica; SB - saturação por bases; CTC - capacidade de troca catiônica; V - saturação por bases; $m$ - saturação por alumínio. 
As semeaduras foram realizadas distribuindo-se seis sementes de $M$. cissoides, quatro de $S$. aterrimum e 12 de $N$. wightii por vaso, na profundidade de $2 \mathrm{~cm}$, constante para todas as parcelas. Os vasos foram irrigados sempre que se julgou necessário, sem a ocorrência de deficiência hídrica.

Para cada avaliação, quatro plantas (repetições) foram aleatoriamente amostradas pelo método destrutivo; elas passaram por lavagem em água corrente, para retirada do solo remanescente nas raízes, e, em seguida, tiveram suas variáveis analisadas. A área foliar (Af; $\mathrm{cm}^{2}$ por planta) das amostras foi obtida com auxílio do medidor de área modelo LICOR LI-3100 (LICOR, inc., Lincoln, Nebraska, EUA), depois da lavagem das raízes. O material amostrado foi seco em estufa a $70^{\circ} \mathrm{C}$ por 72 horas, quando se mensurou também a matéria seca ( $g$ por planta) das raízes $(M r)$, da parte aérea $(M a)$ e total $(M t)$.

Assim, em cada avaliação, com os valores primários da variável matéria seca total, pôdese calcular a taxa de crescimento absoluto e a taxa de crescimento relativo (Aguilera et al., 2004; Carvalho et al., 2008). A taxa de crescimento absoluto foi obtida com base na seguinte fórmula:

$$
G_{M}=\frac{M t_{2}-M t_{1}}{t_{2}-t_{1}}
$$

em que $M t_{1}$ e $M t_{2}$ são as matérias secas de duas amostras sucessivas; e $t_{1}$ e $t_{2}$, os dias decorridos entre as duas observações. Por sua vez, a taxa de crescimento relativo foi calculada com base na fórmula:

$$
R_{M}=\frac{\ln M t_{2}-\ln M t_{1}}{t_{2}-t_{1}}
$$

A análise estatística dos dados foi realizada por meio da aplicação do teste $\mathrm{F}$ na análise da variância. As espécies foram comparadas pelo teste de Tukey a 1\% de significância. As variáveis quantitativas, relacionadas com o crescimento das plantas, foram analisadas por meio de regressões não lineares, com o objetivo de modelar os dados sob a forma de equações.
As variáveis matéria seca da parte aérea, raízes, matéria seca total e área foliar foram ajustadas ao modelo de regressão não linear do tipo logístico, adaptado de Streibig (1988):

$$
y=\frac{a}{\left[1+\left(\frac{x}{b}\right)^{c}\right]}
$$

em que $y$ é a variável-resposta de interesse; $x$, o número de dias acumulados; e $a, b$, e $c$, parâmetros estimados da equação ( $a$ é a amplitude entre o ponto máximo e o ponto mínimo da variável, $b$ corresponde ao número de dias necessários para a ocorrência de $50 \%$ de resposta da variável e cé a declividade da curva ao redor de $b$ ).

A variável crescimento absoluto foi ajustada ao modelo de regressão não linear do tipo logístico, adaptado de Carvalho et al. (2008):

$$
y=a+b \cdot 4 \cdot \frac{\exp \left[-\left(\frac{x-c}{d}\right)\right]}{1+\exp \left[-\left(\frac{x-c}{d}\right)\right]}
$$

em que $y$ é a variável de interesse; $x$, o número de dias acumulados; e $a, b, c, d$, parâmetros estimados da equação.

A variável crescimento relativo foi ajustada ao modelo de regressão não linear do tipo log normal.

$$
y=a+b \times \exp \left[-0,5 \times\left(\ln \frac{\left(\frac{x}{c}\right)}{d}\right)\right] \times\left[\ln \left(\frac{\frac{x}{c}}{d}\right)\right]
$$

em que $y$ é a variável de interesse; $x$, o número de dias acumulados; e $a, b, c, d$, parâmetros estimados da equação.

\section{RESULTADOS E DISCUSSÃO}

Acredita-se que a análise do crescimento das plantas ainda seja a forma mais simples

Planta Daninha, Viçosa-MG, v. 30, n. 3, p. 497-504, 2012 
e precisa para quantificar a contribuição dos diferentes processos fisiológicos para o crescimento vegetal, sendo aplicável no estudo de variações entre plantas geneticamente diferentes ou quando submetidas a diferentes condições ambientais. Com a análise do crescimento, torna-se possivel conhecer a cinética de produção de biomassa das plantas, sua distribuição e eficiência ao longo da ontogenia (Aguilera et al., 2004; Carvalho et al., 2008).

A taxa de crescimento absoluto $\left(G, \mathrm{~g} \mathrm{dia}^{-1}\right)$ fornece uma estimativa da velocidade média de crescimento das plantas ao longo do ciclo de desenvolvimento; a taxa de crescimento relativo $\left(R, \mathrm{~g}^{-1} \mathrm{~g}\right.$ dia $\left.^{-1}\right)$ exprime o crescimento em gramas de matéria seca por unidade de material presente em um período de observação (Evans, 1972; Aguilera et al., 2004). As espécies que crescem rapidamente produzem mais área foliar e, possivelmente, serão mais competitivas que aquelas de crescimento lento (Horak \& Loughin, 2000).

A característica biológica de crescimento inicial pode conferir à espécie baixa ou alta competitividade interespecífica no interior dos campos agrícolas, em especial na cultura da cana-de-açúcar, onde, para as espécies $N$. wightii e $M$. cissoides, foi observado crescimento inicial lento; entretanto, tratase de plantas daninhas com alta capacidade de interferência na colheita mecanizada da canade-açúcar, sendo necessário o manejo correto para evitar perdas de rendimento operacional e cultural. Já a espécie $S$. aterrimum demonstrou alta capacidade de crescimento inicial, podendo apresentar alta competitividade com a cana-de-açúcar já no início do seu ciclo (Figura 1A)

Os parâmetros $a, b$ e $c$ do modelo logístico, para todas as variáveis do experimento, estão apresentados na Tabela 2. Esses parâmetros foram necessários para elaboração dos gráficos e dos ajustes dos dados de acúmulo de matéria seca e área foliar, taxa de crescimento relativo e absoluto durante o período de ciclo estudado para as três espécies. Para todas as variáveis, constatou-se efeito das espécies, bem como das interações.

A estabilização da matéria seca das espécies foi detectada a partir dos 100 DAS (Figura 1). Essa observação está em conformidade com a biologia de $N$. wightii, visto que
Borges et al. (2004) e Pereira (2011) classificaram essa planta como uma espécie perene, com a característica de crescimento inicial lento, quando comparada com plantas daninhas anuais.

O acúmulo de matéria seca observado demonstra a elevada capacidade que S. aterrimum possui de produzir fitomassa. Pôde-se observar que, aos 70 DAS, as plantas possuíam, em média, valores próximos de $20 \mathrm{~g}$ de $M t$, sendo aproximadamente $17,5 \mathrm{~g}$ correspondentes à participação da $M a$, e os demais $2,5 \mathrm{~g}$, à participação da $M r$. Aos 100 DAS, as plantas já estavam com valores de $M t$ em torno de 25,0 g, com a participação de aproximadamente $21,5 \mathrm{~g}$ e 3,5 g para $\mathrm{Ma}$ e $M r$, respectivamente (Figura 1). Isso corrobora os resultados encontrados por Fernandes et al. (1999), os quais observaram que a planta
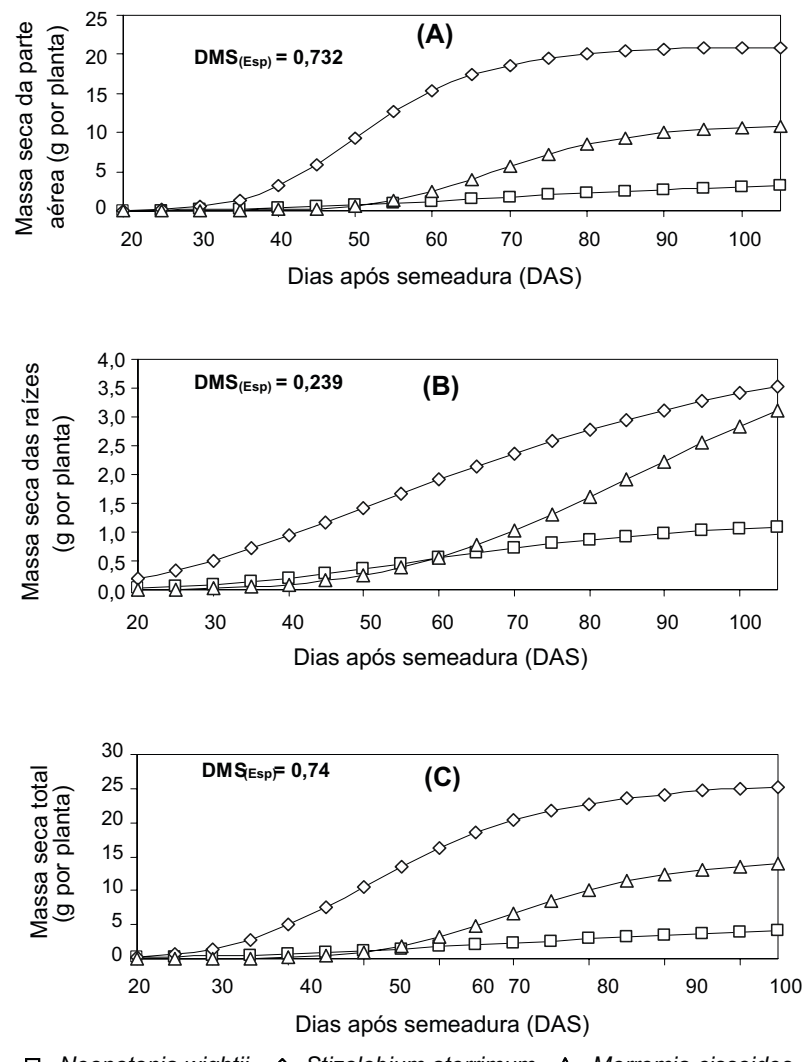

$\neg-$ Neonotonia wightii $\multimap-$ Stizolobium aterrimum $\rightarrow-$ Merremia cissoides

Figura 1 - Acúmulo de matéria seca da parte aérea - Ma (A), matéria seca das raízes $-M r(\mathrm{~B})$ e matéria seca total - $M t(\mathrm{C})$ por planta durante o ciclo de vida das espécies de plantas daninhas $N$. wightii, S. aterrimum e $M$. cissoides. Piracicaba-SP, 2010 
Tabela 2 - Parâmetros dos modelos logísticos e coeficiente de determinação $\left(R^{2}\right)$, obtidos para as variáveis de crescimento analisadas para as espécies $M$. cissoides, $N$. wightii e S. aterrimum. Piracicaba-SP, 2010

\begin{tabular}{|c|c|c|c|c|c|c|c|}
\hline \multirow{2}{*}{ Variável } & \multirow{2}{*}{ Espécie } & \multicolumn{4}{|c|}{ Parâmetro } & \multirow{2}{*}{$R^{2}$} & \multirow{2}{*}{$\mathrm{F}$} \\
\hline & & $a$ & $b$ & $c$ & $d$ & & \\
\hline \multirow{3}{*}{$\begin{array}{l}\text { Matéria seca da parte } \\
\text { aérea }^{\underline{1}}\end{array}$} & M. cissoides & 11,100 & 69,710 & $-8,430$ & - & 0,93 & $33,13 *$ \\
\hline & N. wightii & 4,050 & 74,810 & $-3,800$ & - & 0,99 & $355,62 *$ \\
\hline & S. aterrimum & 21,090 & 51,750 & $-6,730$ & - & 0,96 & $55,93 *$ \\
\hline \multirow{3}{*}{ Matéria seca das raízes ${ }^{\underline{1}}$} & N. wightii & 4,060 & 71,380 & $-16,450$ & - & 0,97 & $77,25^{*}$ \\
\hline & M. cissoides & 4,970 & 94,060 & $-4,600$ & - & 0,97 & $95,84^{*}$ \\
\hline & S. aterrimum & 4,910 & 71,900 & $-2,470$ & - & 0,90 & $27,64 *$ \\
\hline \multirow{3}{*}{ Matéria seca total ${ }^{1 /}$} & M. cissoides & 14,800 & 72,040 & $-7,230$ & - & 0,96 & $62,93^{*}$ \\
\hline & N. wightii & 7,740 & 98,210 & $-2,500$ & - & 0,98 & $112,44 *$ \\
\hline & S. aterrimum & 26,330 & 54,380 & $-4,780$ & - & 0,96 & $65,87^{*}$ \\
\hline \multirow{3}{*}{ Área foliar ${ }^{1 /}$} & M. cissoides & $240.107,000$ & $4.597,000$ & $-1,460$ & - & 0,97 & $89,92 *$ \\
\hline & N. wightii & 584,270 & 66,160 & $-3,730$ & - & 0,97 & $69,36^{*}$ \\
\hline & S. aterrimum & $139.393,700$ & 716,120 & $-1,920$ & - & 0,94 & $40,95^{*}$ \\
\hline \multirow{3}{*}{ Crescimento absoluto $^{\underline{2} /}$} & M. cissoides & 0,034 & 0,781 & 92,136 & 7,526 & 0,99 & $137,66^{*}$ \\
\hline & N. wightii & 0,002 & 0,093 & 85,223 & 15,446 & 0,97 & $49,18^{*}$ \\
\hline & S. aterrimum & 0,113 & 0,883 & 64,674 & 5,518 & 0,96 & $29,32 *$ \\
\hline \multirow{3}{*}{ Crescimento relativo $^{\underline{3} /}$} & M. cissoides & 0,005 & 0,068 & 48,895 & 0,480 & 0,95 & $32,74 *$ \\
\hline & $N$. wightii & $-0,001$ & 0,067 & 41,012 & 0,645 & 0,91 & $17,90 *$ \\
\hline & S. aterrimum & 0,008 & 0,108 & 54,014 & 0,117 & 0,94 & $22,91 *$ \\
\hline
\end{tabular}

${ }_{(1 /} /$ Modelo: $\left.\mathrm{y}=\mathrm{a} /(1+(\mathrm{x} / \mathrm{b}) \mathrm{c})\right) ;{ }^{2 /}$ Modelo: $\left.\left.\mathrm{y}=\mathrm{a}+\mathrm{b}^{*} 4.0^{*}\{\exp [-(\mathrm{x}-\mathrm{c}) / \mathrm{d})] /[1.0+\exp [-(\mathrm{x}-\mathrm{c}) / \mathrm{d})]\right]\right\} ;{ }^{1 /}$ Modelo: $\mathrm{y}=\mathrm{a}+\mathrm{b}^{*} \exp \left\{-0,5 *[\mathrm{LN}(\mathrm{x} / \mathrm{c}) / \mathrm{d}]^{*}\right.$ $[\mathrm{LN}(\mathrm{x} / \mathrm{c}) / \mathrm{d}]\}$. ${ }^{*}$ Teste $\mathrm{F}$ significativo a $1 \%$ de probabilidade.

S. aterrimum, utilizada como adubação verde, produziu $28 \mathrm{~g}$ por planta de $M t$, também aos 100 DAS.

Trabalhando com outra espécie de planta daninha, Carvalho et al. (2005a) observaram valores de $M t$ próximos a $25 \mathrm{~g}$ por planta para Rottboelia exaltata, aos 75 DAE. Nesse mesmo sentido, Carvalho et al. (2005b), em outro trabalho de análise de crescimento, constataram valores próximos a $30 \mathrm{~g}$ por planta de $M t$ para Chloris polydactyla, aos 100 DAS.

Para as espécies $N$. wightii e M.cissoides, foram encontrados valores menos expressivos, pois aos 100 DAS observaram-se valores de 4 e $14 \mathrm{~g}$ para $M t$, respectivamente, com participação de $3 \mathrm{~g} M a$ e $1 \mathrm{~g} M r$; para $N$. wightii e $M$. cissoides, os valores foram de $10 \mathrm{~g} \mathrm{Ma}$ e $4 \mathrm{~g} \mathrm{Mr}$, respectivamente (Figura 1). Esses resultados corresponderam aos valores encontrados para Richardia brasiliensis: $16 \mathrm{~g}$ por planta de $M t$, aos 140 DAS (Pedrinho Júnior et al., 2004).
No início do ciclo, pôde-se observar maior participação da $M r$ com relação à $M t$ para a espécie $N$. wightii, evidenciando a característica desta planta em desenvolver rapidamente seu sistema radicular. $O$ rápido desenvolvimento da estrutura radicular com posterior formação de parte aérea favorece a dominação do espaço em que a planta está se desenvolvendo, principalmente em função da maior taxa de absorção de água e nutrientes, com crescente interceptação da radiação incidente.

Quanto a $S$. aterrimum, em consequência da elevada produção de matéria pela parte aérea, pôde-se demonstrar a habilidade dessa planta daninha em acumular fitomassa, sendo essa uma das principais características biológicas da espécie que determina sua competitividade com as culturas agrícolas e cobertura do solo em áreas de rotação de cultura.

A variável área foliar (Af) acompanhou o ganho de matéria pela parte aérea, nas três

Planta Daninha, Viçosa-MG, v. 30, n. 3, p. 497-504, 2012 
espécies estudadas; contudo, próximo do final do experimento, observou-se estabilização da matéria seca da $M a$, sendo constado o ponto máximo de aproximadamente $3.500 \mathrm{~cm}^{2}$ de área foliar para $S$. aterrimum, $1.000 \mathrm{~cm}^{2}$ para M. cissoides e $500 \mathrm{~cm}^{2}$ para $N$. wightii (Figura 2). Em estudo semelhante, com plantas daninhas do gênero Amaranthus, Carvalho et al. (2008) observaram valores entre 2.000 e $4.000 \mathrm{~cm}^{2}$ para as espécies estudadas, sendo em torno de $4.000 \mathrm{~cm}^{2}$ para $A$. retroflexus e A. hybridus aos 60 DAS e $2.000 \mathrm{~cm}^{2}$ para A. deflexus.

No entanto, para $S$. aterrimum, próximo do final do experimento, observou-se estabilização da $M a$ e da $M T$, tendo-se 25 g por planta para $M t$, com a participação de 22,5 g por planta pela $M a$ e 3,5 g por planta pela $M r$.

Tanto para os dados de matéria seca de folhas (Figura 1A) e área foliar (Figura 2), $S$. aterrimum foi a espécie que alcançou maiores magnitudes; em condição intermediária, identificaram-se $M$. cissoides e $N$. wightti, com o menor acúmulo dessas variáveis.

Esses dados estão em concordância com os valores de matéria seca total (Tabela 2).

Um fato observado foi o grande número de folhas em $N$. wightii, que não se refletiu em elevada área foliar devido ao tamanho reduzido das folhas produzidas em todas as ramificações. Já S. aterrimum e $M$. cissoides produziram folhas posicionadas na haste principal e nas ramificações primárias, o que se refletiu em folhas de maior tamanho.

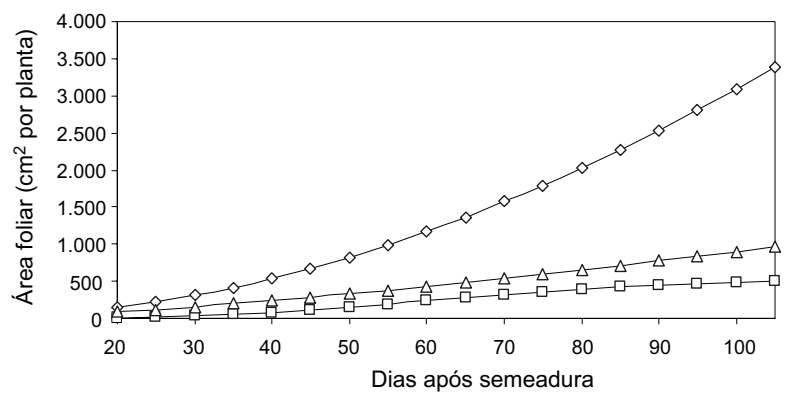

$\neg \square$ Neonotonia wightii $\diamond-$ Stizolobium aterrimum $\neg-$ Merremia cissoides

Figura 2 - Área foliar $(A f)$ por planta durante o ciclo de vida das espécies N. wightii, S. aterrimum e M. cissoides. Piracicaba-SP, 2010.
No caso da planta daninha $S$. aterrimum, a taxa de crescimento absoluto foi estável no início do ciclo, com rápido aumento aos 50 DAS e pico próximo aos 65 DAS, o que comprova o crescimento inicial mais rápido que o das outras espécies estudadas. As maiores taxas de crescimento relativo ocorreram próximas do início do desenvolvimento das plantas, em torno dos 45 DAS, com consequente queda ao longo do ciclo (Figuras 3 e 4).

Situação semelhante foi observada para as espécies $N$. wightti e $M$. cissoides, que tiveram suas taxas de crescimento absoluto no final do período estudado, com pico máximo próximo dos 85 DAS para $N$. wightii e aos 90 DAS para $M$. cissoides. Também para as taxas de crescimento relativo, as duas espécies demonstraram valores próximos neste estudo, com as máximas taxas aos 40 e 50 DAS, respectivamente.

A análise conjunta de todas as variáveis e dos parâmetros dos modelos logísticos,
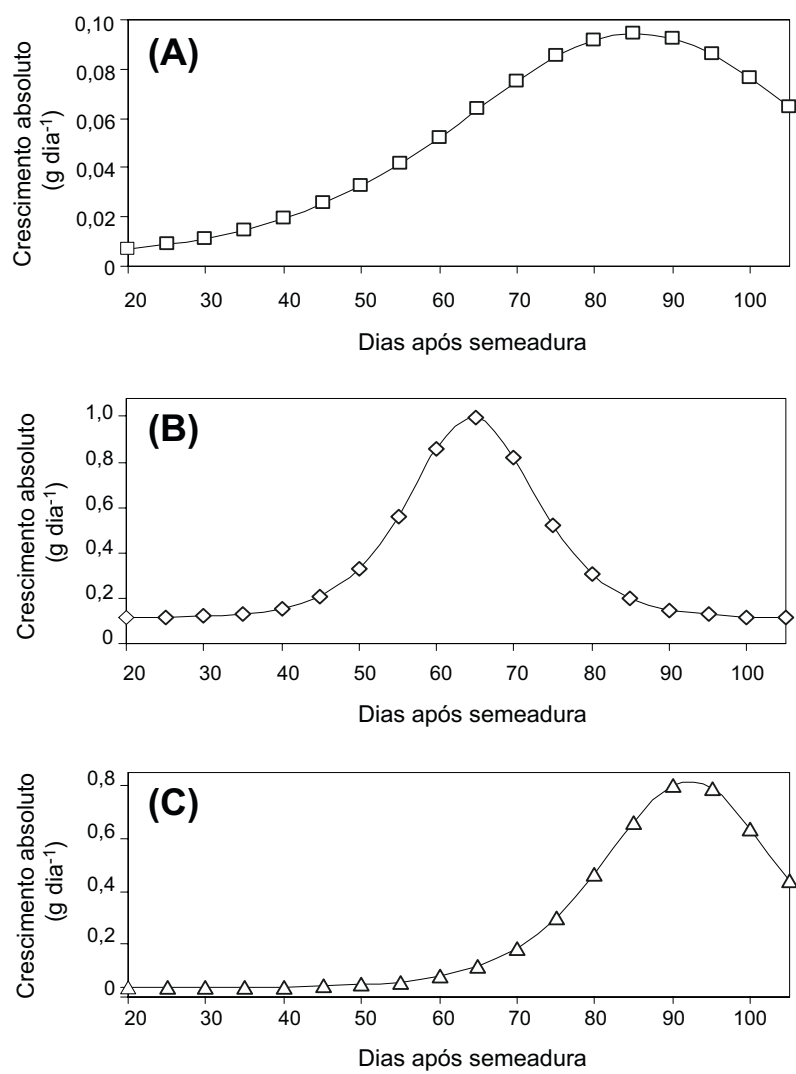

Figura 3 - Taxa de crescimento absoluto durante o ciclo de vida das espécies $N$. wightii (A), S. aterrimum (B) e M. cissoides (C). DMS (0,188). Piracicaba-SP, 2010. 
principalmente quanto ao parâmetro $b$, revela que $S$. aterrimum possui ciclo vegetativo rápido, além de ter sido a primeira espécie a atingir $50 \%$ de matéria em qualquer variável (Figura 1), acúmulo de área foliar (Figura 2) e o período de máxima taxa de crescimento absoluto (Figura 3B). Esse conjunto de características biológicas caracteriza $S$. aterrimum como a espécie que possui a melhor adaptabilidade ecológica para as condições em que o experimento foi realizado. Ainda, esses resultados sugerem que é uma espécie com alto potencial de interferência nas culturas agrícolas, proporcionado pela rápida captura dos recursos de crescimento fornecidos pelo ambiente durante os estádios iniciais de crescimento.

O manejo dessas plantas daninhas precisa ser estruturado com base nos conhecimentos do crescimento e desenvolvimento das espécies, ou seja, as medidas de controle devem ser administradas em período anterior a, aproximadamente, 40 dias de desenvolvimento das plantas, pois a partir desse ponto podem ocorrer problemas com competição por captação de recursos. Da mesma forma, plantas daninhas com crescimento inicial rápido exigem que medidas de manejo sejam adotadas sobre plantas jovens para que os melhores resultados sejam obtidos, uma vez que o desenvolvimento da planta dificulta o controle, e, também, para que a competição entre a planta daninha e a cana-de-açúcar não ocorra ou não seja significativa sobre a produção - características que explicam as razões que podem

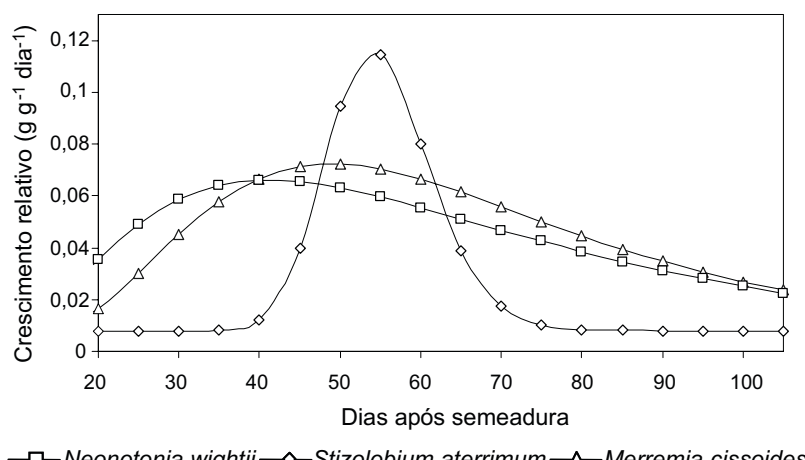

Figura 4 - Taxa de crescimento relativo durante o ciclo de vida das espécies $M$. cissoides (A), S. aterrimum (B) e N. wightii (C). DMS (0,06). Piracicaba-SP, 2010. fazer da planta $S$. aterrimum um problema em potencial para a cultura da cana-de-açúcar, sobretudo em áreas colhidas mecanicamente, devido ao seu alto potencial de emergência em áreas com cobertura de palha de colheita mecanizada crua e profundidade de emergência.

\section{LITERATURA CITADA}

AGUILERA, D.B.; FERREIRA, F.A.; CECON, P.R. Crescimento de Siegesbeckia orientalis sob diferentes condições de luminosidade. Planta Daninha, Viçosa, v. 22, n. 1, p. $43-51,2004$

AZANIA, C.A.M. et al. Manejo químico de Convulvolaceae e Euphorbiaceae em cana-de-açúcar em período de estiagem. Planta Daninha, Viçosa, v. 27, n. 4, p. 841-848, 2009.

BIANCO, S. et al. Estimativa da área foliar de plantas daninhas. XIII - Amaranthus retroflexus L. Ecossistema, Espírito Santo do Pinhal, v. 20, n. 1, p. 5-9, 1995.

BORGES, A.L.; SOUZA, L.S.; CARVALHO, J.E.B. Plantas melhoradoras do solo. Cruz das Almas - BA: EMBRAPA, Embrapa Mandioca e Fruticultura Tropical, 2004.

CARVALHO, S.J.P.; LÓPEZ-OVEJERO, R.F.; CHRISTOFFOLETI, P.J. Crescimento e desenvolvimento de cinco espécies de plantas daninhas do gênero Amaranthus. Bragantia, Campinas, v. 67, n. 2, p. 317-326, 2008.

CARVALHO, S.J.P. et al. Crescimento, desenvolvimento da planta daninha capim-camalote. Bragantia, Campinas, v. 64, n. 4, p. 591-600, 2005a.

CARVALHO, S.J.P. et al. Crescimento, desenvolvimento e produção de sementes da planta daninha capim-branco (Chloris polydactyla). Planta Daninha, Viçosa, v. 23, n. 4, p. 603-609, 2005b.

EVANS, G.C. The quantitative analysis of plant growth. London: Blackwell Scientific, 1972. 734 p.

FERNANDES, M.F.; BARRETO, A.C.; FILHO, J.E. Fitomassa e controle de plantas daninhas em diferentes densidades populacionais de leguminosas. PAB, Brasília, v. 34, n. 9, p. 1593-1600, 1999.

HORAK, M.J.; LOUGHIN, T.M. Growth analysis of four Amaranthus species. Weed Science, Lawrence, v. 48, n. 3, p. $347-355,2000$.

LUCCHESI, A.A. Utilização prática de análise de crescimento vegetal. Anais da Escola Superior de Agricultura "Luiz de Queiroz", Piracicaba, v. 41, n. 1, p. 181-202, 1984.

Planta Daninha, Viçosa-MG, v. 30, n. 3, p. 497-504, 2012 
KUVA, M.A. et al. Fitossociologia de comunidades de plantas daninhas em agroecossistema cana-crua. Planta

Daninha,Viçosa, v. 25, n. 3, p. 501-511, 2007.

OLIVER, D. Importance of weed biology to weed management: proceedings of a symposium presented at the Weed Science Society of America Meeting in Norfolk, Virginia, February 6, 1996. Weed Science, Lawrence, v. 45, n. 3, p. 328, 1997.

PEDRINHO JÚNIOR, A.A.F.; BIANCO, S.; PITELLI, R.A. Acúmulo de matéria seca e macronutrientes por planta de Glycine max e Richardia brasiliensis. Planta Daninha, Viçosa-MG, v. 22, n. 1, p. 53 - 61, 2004.
PEREIRA. J.M. Produção e persistência de leguminosas em pastagens tropicais. In: SIMPÓSIO DE FORRAGEIRAS E PASTAGENS, 2., 2001, Lavras. Anais... Lavras: UFLA, 2001. p. 111-142.

RADOSEVICH, S.; HOLT, J.S.; GHERSA, C. Weed ecology: implications for vegetation management. New York: John Willey, 1997. 589 p.

STREIBIG, J.C. Herbicide bioassay. Weed Research, Oxford, v. 28, n. 6, p. 479-484, 1988 